Article

\title{
Sustaining Multilingualism in Chinese Universities: Uzbekistani Students' Demotivation While Learning Chinese
}

\author{
Meilan Liu ${ }^{1}$, Yongyan Zheng ${ }^{2, *}$, Xiuli Ma ${ }^{3}$ and Yuxin Wei ${ }^{1, *}$ \\ 1 College of Humanities and Foreign Languages, China Jiliang University, Hangzhou 310018, China; \\ liuml@cjlu.edu.cn \\ 2 College of Foreign Languages and Literature, Fudan University, Shanghai 200433, China \\ 3 Global Learning Center, Yamanashi Gakuin University, Yamanashi 400-8575, Japan; m-xiuli@ygu.ac.jp \\ * Correspondence: yongyanzheng@fudan.edu.cn (Y.Z.); wtilda1122@gmail.com (Y.W.)
}

Received: 27 July 2020; Accepted: 10 September 2020; Published: 14 September 2020

\begin{abstract}
This paper reports on a mixed method study exploring demotivation among Uzbekistani students while they are learning Chinese in a Chinese university. In the study, we conducted a survey among 67 Uzbekistani students, and interviewed 30 of them about their experiences of learning Chinese. The analysis of the data revealed that a lack of self-confidence, insufficient learning opportunities, a lack of learning support, and teacher qualities were the most salient factors affecting Uzbekistani students' demotivation while learning Chinese. In light of the findings, we put forward suggestions for language educators and educational administrators in order to enable them to enhance language learners' interest in and enthusiasm for learning Chinese, so that they will sustain their learning efforts and Chinese universities can achieve sustainable multilingualism.
\end{abstract}

Keywords: motivation; demotivation; Uzbekistani students; Chinese language learning

\section{Introduction}

Research has long noted that sustainable and successful language learning is closely associated with language learners' drive to learn languages. For this reason, the construct of motivation has emerged as one of the most frequently-used concepts for explaining the sustaining and success of language learning, e.g., [1-5]. To date, most studies have focused on what motivates learners to learn languages well, but little has been done to reveal what demotivates learners from investing their efforts in language learning. Studies on language learners' demotivation may also generate important insights to enable language educators and educational administrators to support and sustain language learners' learning efforts.

Due to China's remarkable economic development over the last few decades, the Chinese language has become a globally-important language with an increasing number of learners studying it, e.g., [6,7]. A growing number of international students have also come to China to learn Chinese, hoping to benefit from an intensive and immersive learning experience. In 2018, according to the statistics published by the Ministry of Education of the People's Republics of China, the number of international students in China reached 490,000, with 250,000 of them coming to pursue an undergraduate degree. In particular, a large number of international students from countries in Central Asia have arrived in China in order to undertake short-term language learning courses and long-term academic studies for university degrees in the medium of English or Chinese, driven by the launch of China's Belt and Road Initiative, e.g., [8].

Recently, due to the cooperative educational program between Central Asian countries and Zhejiang provincial Municipal, many Uzbekistani senior high school graduates have been encouraged 
to study in some of the universities of Hangzhou City, Zhejiang Province, China. In most universities in Hangzhou, international students are provided with a Chinese language-related course every day, such as Comprehensive Chinese, Chinese Characters and Writing, and Chinese Listening and Speaking. These courses are comprehensive for students; each course takes 90 mins each time. The HSK (Hanyu Shuipin Kaoshi: Chinese Language Proficiency Test) standard book is used as students' main learning material; supplementary electronic materials are also provided by the colleges and teachers. The students are encouraged to spend time on self-learning after class. The lecturers use mixed methods in class in order to keep classes active. However, we and many other teachers noted that demotivation emerged as a significant phenomenon. Among these students, compared to other international students from other countries in college, Uzbekistani students' demotivation stood out; for example, some of the students were frequently late or absent for their Chinese language class; in many cases, half of these students would enter the classroom in the middle of class; they did not participate in class learning activities, and some of them often failed to submit assignments on time, with excuses such as "I forgot taking it with me" and "I have no time to do it". These issues suggest that the students might have gone through a process of declining motivation related to learning Chinese.

It has become increasingly necessary for language educators and educational administrators to understand foreign students' experiences of learning Chinese in China in order to enable effective and sustainable language learning in these students. In order to address these disciplinary and practical needs, this study will explore what demotivates Uzbekistani students when learning Chinese.

We intend to work out some strategies that language educators and educational administrators may use in order to enhance students' motivation and promote their sustainable learning of Chinese. Before we present the study itself, however, we will discuss the construct of demotivation in language learning research.

\section{Literature Review}

Demotivation is defined as "specific external forces that reduce or diminish the motivational basis of a behavioral intention or an ongoing action" [2] (p. 124). Demotivated language learners are language learners who were once motivated but have lost their commitment or interest for some reason [2]. Though most studies have focused on what motivates learners to learn, some studies have examined possible factors that might contribute to learners' demotivation. For instance, Kikuchi [9] identified five demotivation factors from a survey of forty-seven students in different universities, including the individual teachers' behaviour in the classroom, the grammar-translation method used in the instruction, tests and university entrance examinations, the memory-based nature of vocabulary learning, and textbook/reference book-related issues. This study also found that the teacher-related factors which possibly cause demotivation in second language learning included, for instance, one-way teaching, unclear pronunciation, a fast teaching pace, a lot of homework, bad responses to questions, critical attitudes towards students' classroom performance, and a soft voice. Teachers' behaviour was also a top-ranking factor in other studies [10-12].

Limited research has also explored the role of learner-related variables in demotivation for language learning. Studies have argued that language learners' declining motivation is associated with their awareness of the role of their second language and their determination to succeed [13]. Environmental influences from society or the community have also been found to have influenced language learners' demotivation, and studies have also found that the classroom atmosphere is a key factor in learners' motivation [13-20].

Researchers have different opinions about the internal and external factors of demotivation for language learning. Many researchers have found that internal factors may cause demotivation [14,20,21]. However, Dörnyei $[2,3]$ believes that demotivation is mainly caused by external factors. Trang and Baldauf [13] argue that both external factors (e.g., teachers' personality and behaviour) and internal factors (e.g., learners' attitudes, experience of failure and self-esteem) contribute to language learners' demotivation in Vietnam. Falout and Maruyama [14] believe that learners with higher language 
proficiency are more likely to regard external factors, especially teachers, as the main reason for their demotivation, while learners with lower language proficiency tend to see internal factors as the source of their demotivation.

In Chinese contexts, Chang and Cho [22] summarised eight factors as the source of English learning demotivation after investigating demotivation among junior high school students in Taiwan. The eight factors included learning difficulties, threats to self-worth, monotonous teaching, poor teacher-student relationships, punishment, anxiety, a lack of self-determination, and poor classroom management. Zhang [23] believed that improper behaviour in terms of the teacher's immediate reaction and a negative classroom atmosphere are the two main reasons for the reduction of students' motivation. Zhang and Ding [24] summarised that cognitive factors related to individual language learners, such as reduced self-efficacy, negative emotions and missing learning goals, lead to declining motivation in their second language learning. Research on learning Chinese as an additional language has also identified that decreased self-confidence directly affects the intensity of learning motivation among Chinese learners [25]. $\mathrm{Xu}$ [26] also mentioned that learner-related factors are essential in demotivation.

Some researchers also start to explore the variables in demotivation for learners who are learning Chinese as a foreign language. Based on the research on Mongolian students' demotivation in Chinese language learning, Demberel [27] found that family factors, teaching methods, course content and the language itself can influence learners' motivation and lead to demotivation among them. Jeong [28] summarized that the indoctrination teaching method and humdrum learning materials impair Korean students' motivation in Chinese language learning; it was also noted that excellent Chinese language learners in advanced levels have a positive impact on common students. Pretty [29] investigated the college students' demotivation in learning Chinese in the University of Zimbabwe, revealing that the main demotivation factors are instructors' poor teaching methods and behavior. It was found in [30] that the adult Chinese learners in Zimbabwe benefit greatly from distance and network teaching; because of the wrong attribute, it often makes the students form negative thoughts and become demotivated. Ko [31] focused on the Korean international students in China, showing that teacher-related factors are salient in demotivation. In simple terms, teacher-related factors are most likely to cause demotivation, no matter whether in English or Chinese language learning. To summarise, teacher-related and environment-related factors are considered to be the most salient when discussing demotivation among students, which are both external factors, while internal factors-such as determination, self-confidence, self-esteem, and negative emotions-are also important. However, more studies are needed to identify what demotivates learners when learning Chinese as a foreign language or as an additional language, especially in the context of the adaption period before formal higher education in China.

\section{The Inquiry}

This research will explore what demotivates Uzbekistani students from learning Chinese, and will address the following research questions:

- What demotivates Uzbekistani students from having pre-sessional Chinese language courses at Chinese universities?

- What are the internal and external factors for this demotivation? Which external and internal factors significantly contribute to demotivating Uzbekistani students from learning Chinese at universities in Hangzhou?

- What are the differences between the beginners' and the intermediate level students' main source of demotivation?

The study is a mixed method enquiry into Uzbekistani students' learning of Chinese, with a focus on their demotivation. A total of 67 students participated in the survey; 30 of them who could speak both Uzbek and English also took part in follow-up interviews. The university where these students were learning Chinese is located in Eastern China. The Chinese language the students were learning is the national standard written and spoken variety (Putonghua), but the Chinese language has many 
regional varieties, which are quite different from the national standard in terms of phonology, grammar and lexis, e.g., [32]. Though many people in the local community of the university speak Putonghua, they also speak their own regional variety of the Chinese language, which differs phonetically and grammatically from Putonghua. Besides the classroom, the campus is the only place where the students can immerse in the Putonghua context, where they can get lasting help from Chinese peer students. Since they are living in international residences and studying with fellows from their native country, it is hard for them to immerse themselves in the Chinese environment totally when they stay in their residences.

\subsection{Participants}

As can be seen in Table 1, the participants included 6 female and 61 male Uzbekistani students aged from 19 to 22 years old. It is notable that the students who came to China to pursue university degrees were denied by universities in Uzbekistan, their native country. Studying in China is another chance for them to obtain an undergraduate diploma or degree, and for this reason they needed to attend a one-year Chinese language course. They only need to take Chinese-related courses in the first year of their undergraduate period; these courses aim to facilitate students with considerable Chinese proficiency in speaking, listening, writing and reading, and a HSK Level 4 Test is used to evaluate their learning outcomes, through which they can commence their undergraduate degree studies. After starting their degree studies, they still need to take Chinese courses once or twice a week. The enquiry took place in the fourth month after their arrival in China, after they had taken one term of the Chinese course. According to the end of term examination results, 49 of them were in the beginner Chinese group and 18 were in the intermediate Chinese group.

Table 1. Basic information about the participants.

\begin{tabular}{cccccccc}
\hline \multirow{2}{*}{ Chinese Language Level } & \multicolumn{2}{c}{ Beginner } & \multicolumn{2}{c}{ Intermediate } & \multicolumn{2}{c}{ Total } \\
\cline { 2 - 7 } & $\boldsymbol{n}$ & $\%$ & $\boldsymbol{n}$ & $\%$ & $\boldsymbol{n}$ & $\mathbf{\%}$ \\
\hline Gender & 2 & 4 & 4 & 22 & 6 & 9 \\
Female & 47 & 96 & 14 & 78 & 61 & 91 \\
Male & \multicolumn{7}{c}{. }
\end{tabular}

\subsection{Instruments}

Informed by Dörnyei's nine demotivation factors, we developed a questionnaire composed of thirty-four questions in order to explore the participants' demotivation in learning Chinese. These questionnaire items covered issues such as self-confidence, negative attitudes, teacher behaviours, academic management, coursebooks, tests and scholarship, activities and facilities, the interference of other foreign languages, and the attitudes of group members (see Table 2). The questionnaire used a Likert scale from to score items from 1 to 5: (1) strongly disagree; (2) disagree; (3) neither agree or disagree; (4) agree; (5) Strongly disagree. The questionnaire also asked the participants to provide background information, such as gender, age and language level. The questionnaire was administered in both Chinese and Uzbek.

After the survey, we conducted interviews by inviting 30 participants in both English and Chinese, 17 from the intermediate level and 13 from the elementary level. The follow-up interviews enabled us to check whether a variety of internal and external factors might have contributed to the participants' demotivation in learning Chinese, including their attitudes toward Chinese language learning, self-confidence, attitudes toward the Chinese community, adaptation after arrival in China, teachers and courses, the attitudes of group members, cultural activities, student associations, facilities and living conditions, and career planning. In the interviews, the participants were encouraged to share why they had come to China and how they had been learning Chinese before we asked them to think about what might have discouraged them from learning Chinese. We also asked them to put forward 
any suggestions for the language educators and educational administrators regarding how to enhance their language learning motivation and experiences. All of the participants were encouraged to talk and express their ideas about the issues above; however, this was not compulsory, and participants were allowed to skip some questions if they did not want to answer or if they thought they were hard to answer. Each interview took about $30 \mathrm{~min}$ and was carried out in a semi-structured manner, in which the participants were encouraged to talk freely about anything that was relevant to the above-mentioned issues.

Table 2. Cronbach analysis results.

\begin{tabular}{|c|c|c|c|c|}
\hline Topics & $\begin{array}{l}\text { Question } \\
\text { Number }\end{array}$ & CITC & $\begin{array}{l}\text { Cronbach's Alpha } \\
\text { If Item Deleted }\end{array}$ & $\begin{array}{c}\text { Cronbach } \alpha \\
\text { Coefficient }\end{array}$ \\
\hline \multirow{2}{*}{ Coursebooks } & 1 & 0.535 & 0.879 & \multirow{34}{*}{0.884} \\
\hline & 2 & 0.269 & 0.884 & \\
\hline \multirow{7}{*}{ Academic management } & 3 & 0.215 & 0.885 & \\
\hline & 4 & 0.408 & 0.881 & \\
\hline & 5 & 0.428 & 0.881 & \\
\hline & 6 & 0.188 & 0.885 & \\
\hline & 7 & 0.634 & 0.878 & \\
\hline & 8 & 0.462 & 0.88 & \\
\hline & 9 & 0.102 & 0.886 & \\
\hline \multirow{11}{*}{ Teachers } & 11 & 0.487 & 0.88 & \\
\hline & 12 & 0.548 & 0.879 & \\
\hline & 13 & 0.511 & 0.879 & \\
\hline & 14 & 0.589 & 0.878 & \\
\hline & 15 & 0.648 & 0.877 & \\
\hline & 16 & 0.265 & 0.883 & \\
\hline & 17 & 0.564 & 0.879 & \\
\hline & 18 & 0.68 & 0.876 & \\
\hline & 19 & 0.731 & 0.876 & \\
\hline & 20 & 0.367 & 0.882 & \\
\hline & 21 & 0.471 & 0.88 & \\
\hline \multirow{2}{*}{ Attitudes of group members } & 22 & 0.219 & 0.884 & \\
\hline & 23 & 0.357 & 0.882 & \\
\hline \multirow{2}{*}{ Self-confidence } & 25 & 0.357 & 0.882 & \\
\hline & 26 & 0.582 & 0.878 & \\
\hline $\begin{array}{l}\text { Interference from other foreign } \\
\text { languages being studied }\end{array}$ & 27 & 0.59 & 0.877 & \\
\hline \multirow{3}{*}{ Tests and scholarship } & 28 & 0.353 & 0.882 & \\
\hline & 29 & 0.427 & 0.881 & \\
\hline & 30 & 0.613 & 0.877 & \\
\hline \multirow{3}{*}{ Negative attitude } & 24 & 0.377 & 0.882 & \\
\hline & 31 & 0.075 & 0.887 & \\
\hline & 32 & -0.12 & 0.89 & \\
\hline \multirow{3}{*}{ Facilities } & 10 & 0.513 & 0.879 & \\
\hline & 33 & 0.141 & 0.886 & \\
\hline & 34 & 0.321 & 0.883 & \\
\hline
\end{tabular}

\subsubsection{Questionnaire Analysis and Results}

The survey data were tabulated using the SPSS statistics program, and the average value of each item in the questionnaire was calculated. We used descriptive statistics to study the particularity of the options, so as to investigate the inclination and difference in each question, as well as the most influential factors affecting demotivation from Chinese language learning. The data for the descriptive statistical analysis in the Appendix A represent a correlation analysis between demotivation 
and the nine predicting variables mentioned above, so as to reveal the main reasons contributing to demotivation in Chinese language learning. For clarity, the horizontal axis in Figure 1 represents the average value of each question, while the vertical axis represents the numbers of the questions. The average value corresponding to the vertical axis is 3 . This table shows the distribution of each item's average value: the higher the value of the option is, the greater the impact that this option has on students' Chinese language learning motivation. For instance, question 25 ranks the highest, at 3.606, and therefore it is shown in the chart as the longest segment on the right-hand side of the chart; question 31 ranks the lowest, with 2.545, and is shown in Figure 1 as the longest segment on the left-hand side of the chart.

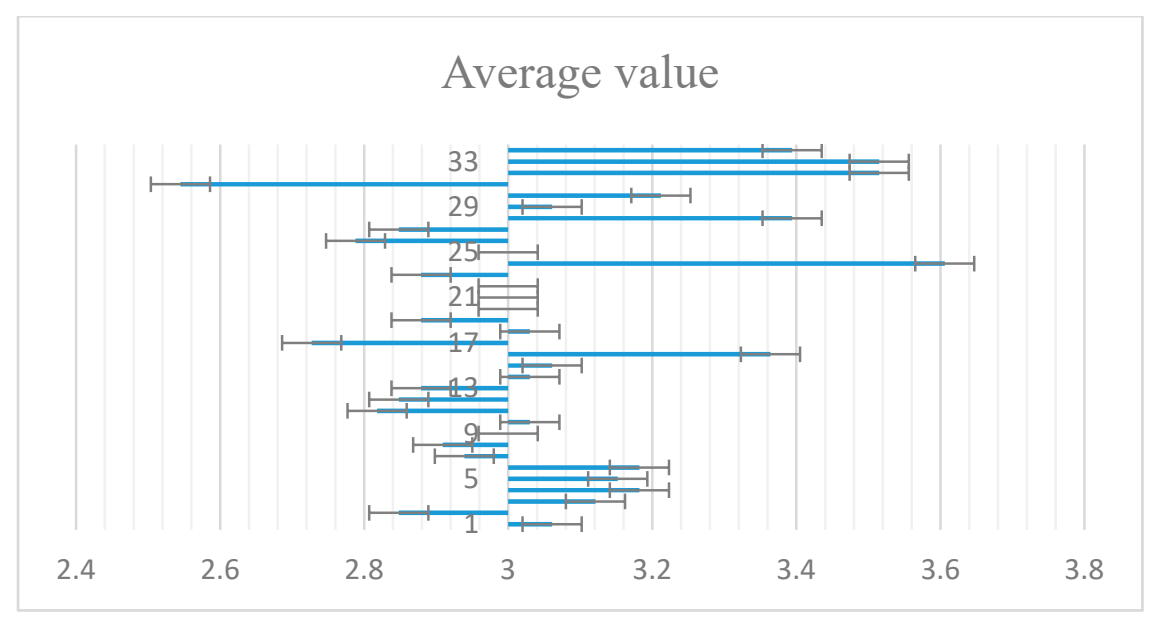

Figure 1. The average values of the items in the descriptive statistical analysis.

Next, we used the Cronbach's alpha reliability coefficient to calculate and determine the internal-consistency reliability of the questionnaire. According to the data results shown in the analysis (Table 2), the Corrected Item-Total Correlation (CITC) values of three items, namely "Frequent replacement of teachers has affected my learning", "The request for class leave is too strict", "There is no cultural activity/association for international students to participate" were less than 0.2 . This means that the correlation between these question items and the remaining analysis items is weak, and they were deleted from the future questionnaire administration. As a result, the Cronbach's alpha for the questionnaire was 0.884 (see Table 2), indicating that the reliability of the finalised questionnaire is high. After we deleted a certain number of the analysed items, there was no significant increase in the coefficient value, indicating that most of the questions in the questionnaire should be retained.

\subsubsection{Interview Analysis and Results}

After recording the interviews, we carefully listened to each part of the interview recording and then transcribed the recordings for analysis. The interview transcripts were sorted and classified into themes according to the frequency of their reference in the interviews. The analysis helped to identify three major themes in the participants' interview data, including 'Self-confidence', 'Activities and facilities', and 'Teachers', capturing the participants' reasons for experiencing demotivation in learning Chinese.

One of the important factors contributing to Chinese language learning demotivation was a lack of self-confidence in language learning, with the participants showing different attitudes towards their willingness to speak Chinese. Further analysis helped us to identify the efforts that the participants had undertaken to learn Chinese apart from attending the Chinese language class, such as self-study. We also read the data to discover what they thought about the learning environment for learning Chinese at the university, and their opinions on their teachers were also carefully examined in order to identify how these influenced the participants' demotivation and efforts in learning Chinese [13]. 


\section{Findings}

The analysis of the questionnaire and interview data revealed that the participants were demotivated to learn Chinese for reasons related to a mix of both external and internal factors, including the participants themselves and their learning context. In particular, the participants mentioned the external factors-such as language teachers, and insufficient activities and facilities related to the learning and use of Chinese-as major sources of demotivation. Besides this, internal factors were also found in this research; the analysis of the questionnaire data identified negative attitudes as another major source of demotivation, while the interview data suggested that the participants' self-confidence was also an influencing factor.

\subsection{The Questionnaire Results}

We analyzed the questionnaire data to determine the most influential sources of demotivation relating to the participants' learning of Chinese (see the Appendix A). The four items that received the highest average values are listed in Table 3.

Table 3. Sorting of the items with highest average values.

\begin{tabular}{ccc}
\hline Rank & Average Value & \multicolumn{1}{c}{ Demotivation Reasons } \\
\hline 1 & 3.606 & • Although I study hard, there's still no progress in my Chinese proficiency \\
\hline 2 & 3.515 & $\begin{array}{l}\text { ・ I felt that Chinese is so difficult for me } \\
\bullet\end{array}$ \\
\hline 3 & 3.394 & $\bullet$ There is no cultural activity or association for foreign students to take part in \\
\hline
\end{tabular}

Table 3 suggests that the participants were demotivated to learn Chinese because they felt that they had made "no progress in [their] Chinese proficiency", despite the effort that they had devoted to the learning process. This seems to echo a widespread perception among the participants that Chinese is a difficult language. Similarly, the participants also complained about a lack of cultural activities or associations for them to participate in, and the lack of language support groups to facilitate their learning of Chinese. These results suggest that the participants' demotivation for learning Chinese was closely associated with their perceptions of the Chinese language and their own learning processes, and that it was also to do with their perceived language learning environments. All these sources of demotivation were further supported by the participants' narratives about learning Chinese, as documented in the next section.

\subsection{The Interview Results}

Most of the interviewed participants (75\%) admitted that they were attracted to come to China and motivated to learn Chinese because they believed that they would benefit from improved career opportunities. The following response from Jamol captures most of the participants' experience:

"Our country provides us with this opportunity, and my parents support me to do this, and I am curious about Chinese culture. In the future, I want to do business in China". (Jamol, elementary level)

As can be seen from this quote, the participants regarded their academic studies and learning of Chinese as an investment, hoping that they would ultimately gain valuable business and career opportunities. However, the interview data confirmed the challenges that they experienced-which were also indicated by the questionnaire results-contributed to their demotivation in relation to learning Chinese. Specifically, the participants experienced many frustrations in learning and using the Chinese language, causing them to be less confident and become demotivated. They also felt that the learning environment was not supportive enough, and they hoped that Chinese language teachers might change their ways of teaching to facilitate their learning. 


\subsubsection{Frustrations in Learning and Using Chinese}

Most of the participants referred to their stress and frustrations related to the learning and use of Chinese. They found it highly stressful to talk to local Chinese students or staff, because the participants did not know how to speak Chinese properly. Participants, such as Shawn, complained about putting a lot of effort into learning Chinese every day, but these efforts seemingly had little effect on their Chinese proficiency development:

"Initiative? Well, I could speak Chinese with my classmates, of course, and we usually speak Chinese in the campus, especially when having lunch or dinner in the canteen, I mean, talk to the staff on campus. Usually I prefer not to talk to the locals outside the campus because I don't know how to express myself. Why? Because the language is so hard, and it is becoming harder than before. I am stressed, not sure if I can learn well later". (Shawn, elementary level)

The perception that Chinese is an extremely difficult language to learn was widespread among the participants. It is noteworthy that Shawn uses his frustrations related to learning Chinese to question whether he will be able to learn it well. In other words, he recognises the perceived difficulties related to learning Chinese as a significant reason for him to feel demotivated about learning the language. Like Shawn, other participants also mentioned that they were not sure about their pronunciation, or that they felt anxious and stressed when talking to Chinese people, which seems to have discouraged them from putting more effort into learning and using Chinese.

We also noted that the particular linguistic context, where regional varieties of Chinese other than the national standard that these students were learning are used in the local community, may have caused further confusion for the participants. For instance, Samander, a student from the intermediate Chinese proficiency group, was quite positive about his interaction with locals, as he believed that such interactions present good opportunities for practicing the language. He was helped by staff in the university library twice, and helped by some passers-by when asking for directions at scenic spots in the downtown area of the city. However, he was quite confused about the Chinese language after interacting with some senior citizens in the local community:

"I did (talk to locals) sometimes, because, you know, it is a good way to practice. But it's hard to tell what the senior citizens were saying, the language they were using is definitely not Putonghua". (Samander, intermediate level)

Samander's experience was shared by the other participants in the intermediate proficiency group, who were more confident in interacting with local students and staff on campus than those in the beginner proficiency group. Nevertheless, most of these participants also hesitated to interact with locals in the community. It is very likely that the participants were unable to understand what the locals, particularly local senior citizens, were saying because they were using regional varieties of Chinese that are significantly different from the version that the participants were working hard to learn and master. This may add to their feeling of frustration when learning what they already perceive to be a very difficult language. It also explains why they may not be able to fully access supportive learning environments.

\subsubsection{Lack of Opportunities and Facilities for Learning and Using Chinese}

Apart from the frustrations that they experienced in learning and using Chinese, the participants also mentioned that they had limited access to on-campus facilities and opportunities, such as cultural activities that would help them to learn and use Chinese outside the language classroom. For instance, John compared the study space at the Chinese university with that in a school he had previously attended in Dubai: 
“The library is so cold, especially in the winter, they didn't turn on the air-conditioner even in this case, I was frozen to death! One more thing, I really need somewhere to practice my Chinese speaking, but there is no small seminar room provided in the library so I cannot speak aloud. In Dubai, the previous school I attended does have a seminar room, it was good". (John, elementary level)

The library in the Chinese university has a lot of space for students to study quietly, but it does not have small seminar rooms for students' group work. For this reason, it was difficult for participants like John to organise a conversation group to support their use of Chinese in a secure venue. The absence of group seminar rooms frustrated the participants' attempts to practice Chinese in groups without having to face the public. Because the participants usually found it stressful to use Chinese in public, they also felt unable to overcome the hurdle of discomfort and uneasiness while they were investing efforts to improve their Chinese proficiency.

They also needed guidance in learning Chinese. As mentioned earlier, many of them had come to China and decided to learn Chinese in pursuit of better career opportunities, but this initial motivation was apparently in need of bolstering, since some of the participants were not sure about what to do in the future after their departure from China. This was described by Shams:

"I am not sure what I am going to do in the future, and I suddenly can't find the point of learning Chinese, I guess it would be better if there is any place where I can consult with someone about my future career plan or something". (Shams, intermediate level)

It is understandable that the participants might have begun to question the use of Chinese in relation to their future, after their experience of the frustrations associated with learning and using the Chinese language. For this reason, participants like Shams would have benefited from further guidance. Otherwise, he would continue to feel demotivated about his efforts to learn a language that was difficult for him.

Other participants also talked about the challenges they experienced in learning Chinese, and complained that they had no one to ask for help when they needed assistance to overcome these challenges:

"I am confused all the time, but my teachers do not always have time to answer my questions, I understand, I thought we need a person who can help us to fix the problems related to learning". (Jamol, elementary level)

This lack of guidance and support caused additional frustration for the participants in the process of learning Chinese, which further undermined their motivation to learn the language. The participants were also highly interested in the cultural activities organised by the students and staff, which helped them to familiarise themselves with Chinese culture, but they felt that more such cultural activities targeting their levels of Chinese should be organised in order to sustain their motivation for learning the language.

\subsubsection{Teachers and their Teaching Style}

It must be noted that most of the participants thought highly of their teachers and Chinese classes, but they were demotivated in their efforts because they had different priorities in relation to learning Chinese. It is probably not surprising that the participants were highly preoccupied with the HSK: the examination they had to pass so that they could start their academic degree studies in the Chinese university. Jack said that their teachers sometimes believed that it was important for the participants to learn more than what they needed to for the HSK: 
"I hope that the teacher can focus on the grammar of our HSK standard course book systematically. For example, the first time they teach some function words, he or she can tell us all usages of the word, it would be clearer. And you know what, sometimes the teacher gives us some assignments but does not give or gives little feedback, which confused and discouraged us. This is not beneficial to our studies". (Jack, intermediate level)

It could be argued that the participants might have failed to consider that their Chinese language teachers wanted to teach them useful language, because the HSK standard book outline for vocabulary and characters is often considered rather impractical [33].The participants also wanted to receive more feedback from their teachers regarding their assignments, because the limited amount of comments that the teachers gave them 'confused' and 'discouraged' them in learning and using Chinese.

It is worth noting that, during this research, we found that some of the teachers are not professional TCSOL teachers; they are Chinese literature teachers who were invited by the college to make up the shortage of language teachers, which can also be one of the reasons for students' dissatisfaction. However, it is important for students to communicate with teachers actively, make requirements when necessary, and promote self-learning.

The teachers' pace of teaching was another major source of demotivation, as the participants often had different expectations from the teachers regarding classroom management. For instance, participants like John, who experienced a lot of challenges in learning Chinese, wanted the teacher not only to focus on helping him to pass the HSK test but also to have a reasonable teaching pace, so that he could follow them:

"The teachers taught too fast. Other teachers started their classes earlier than us by half a month, and now the progress we are taking is the same as theirs, it is not reasonable, our class is almost finishing the HSK2, it is too fast, we cannot digest what we learnt well". (John, elementary level)

The participants who struggled with learning Chinese understandably found the teaching pace to be another source of stress and frustration, as they found it difficult to cope with the learning demands of the course. These participants risked entering a vicious cycle, as they increasingly missed out on lesson content because of their inability to consolidate what they had learnt in previous classes. Such language learners might become so demotivated that they might start causing disciplinary problems in class. In response to such disciplinary issues, Chinese language teachers might take actions that make other, more highly motivated language learners feel undervalued; this is echoed in the following quote from Zeyn:

"I wish that the teacher would spend less time on the students who do not want to learn, it is a waste of time. Why? These students don't want to learn, because they are coming just for traveling, not for learning". (Zeyn, intermediate level)

In his interview, we sensed Zeyn's frustration that he was missing valuable learning opportunities to improve his Chinese because the teacher needed to expend efforts on the management of other students' behavioural issues. Zeyn was still motivated to learn Chinese, but we felt that his motivation might decrease in the future because he could not achieve his goals in the learning process.

\section{Discussion and Recommendations}

This research aimed to find out what demotivates Uzbekistani students from participating fully in pre-sessional Chinese language courses at Chinese universities? What are the external and internal factors for this demotivation? Which external and internal factors significantly contribute to demotivating Uzbekistani students from learning Chinese at universities in Hangzhou? What are the differences between the beginners and the intermediate level students' main source of demotivation? 
In general, the demotivation factors found in the questionnaire and interview were a mix of both external and internal factors. The external factors include the teacher, and the lack of facilities and activities; the internal factors include students' negative attitudes and lack of self-confidence; among these, the teacher-related factor is the essential one that causes demotivation among Uzbekistani students when learning the Chinese language in the universities of Hangzhou, China.

The research also found that the intermediate level students are generally more confident than beginners in speaking Chinese, even in a diglossic context. Besides this, the difficulties met by beginners and intermediate students are different, which also caused demotivation; for instance, beginners are worried about not speaking Chinese well, and their problems are more related to facility issues; they hope to get more support in learning. However, the intermediate students are worried about not understanding what locals said, and wish to see the opportunities behind the advantages of Chinese language; they also want to have great control over their learning progress.

We appreciate the fact that the participants might have been in a process of cross-cultural adaptation when we conducted this enquiry, since the data collection took place during the fourth month after their arrival into China from Uzbekistan. It is very likely that the participants were still adapting themselves to their new life and academic studies in the Chinese tertiary education environment. It is perfectly natural that they should feel disoriented and feel the need to be supported by caring individuals who can offer guidance and suggestions during the learning process. Nevertheless, we also note that this is a critical stage, since their experiences in the first few months after their arrival in China will have profound influences on their motivation to learn Chinese, and their subsequent educational experiences in the country. For this reason, it is critical to explore and understand what might demotivate them from learning the language; they need to engage with their life and academic studies in the new context.

Based on the findings, the university faculty, Chinese peer students and Uzbekistani students themselves need to make joint efforts to arouse Uzbekistani students' interest in Chinese language and culture, and to inspire them to pursue their dream or future pursuit in China. For instance, university can offer students more guidance and instruction, teachers can help students to understand the cultural gaps by attending classes and tutorials, and the Chinese peer students can provide them with guidance for self-study and living. Besides the external efforts, it is also necessary to promote Uzbekistani students' learning autonomy; making the best use of science and technology to assist learning is prevailing currently; it is a future trend; autonomous learning with the aid of modern technology is a good method, and schools and colleges can provide more e-learning materials, such as recommending Chinese learning apps, opening-up or improving an online language learning platform, providing electronic pre-class learning materials, and so on. Furthermore, the courses for Chinese language learning and culture communication should receive some improvements for the sake of these Uzbekistani students; a vivid class atmosphere should be fostered, and male students' interest orientation should be taken into account, in view of the fact that there are far more male students than female students; further research is also needed on whether traditional ideas about gender would influence students' views on language learning, and to what extent this idea will affect their view on learning Chinese, so that the recommendations proposed by the research can be more specific. In addition, the lack of enough capable Chinese language teachers, and some teachers' inappropriate behaviors, have caused dissatisfaction among students; such issues needed to be discussed among faculties in order to improve teaching quality.

We recognise that their views and responses might change after a longer stay, but we would also contend that our findings constitute an early warning for language educators and educational administrators, hopefully prompting them to undertake efforts so that foreign students may have meaningful, productive experiences while they are learning Chinese and undertaking academic studies in Chinese universities. We also understand that some of these students were refused admission by the universities in Uzbekistan; their initial motivation and academic competence in learning may not have been strong when they first entered the universities in China; their negative emotions, such as anxiety, 
depression, and lack of self-confidence may also cause demotivation, which needs to be studied further. For this reason, we provide the following suggestions-based on the findings of both questionnaire and interview-for language educators and educational administrators who need to support international students regarding their language learning:

1. We would recommend that Chinese universities should establish a learning support centre where international students can ask for help in the process of learning Chinese and pursuing their academic studies. Specialised career counseling for international students like the participants in the study is indispensable, in order to make them aware of the relevance of Chinese proficiency in their future development. The support centre would need to provide language tutoring services for international students, so that they can feel well-supported in the learning process, and their frustrations with learning Chinese may be significantly reduced. They also need consultation services to empower themselves in identifying the most appropriate and effective learning strategies according to their aptitudes, learning backgrounds and learning styles.

2. Chinese universities may also consider creating 'Chinese corners' where international students can practice Chinese socially. This informal social use of Chinese is necessary to ensure that these students can practice their Chinese without the fear of making mistakes. These 'Chinese corners' could be also used to host cultural activities, which encourage international students to use socially-affective strategies to communicate and cooperate with others, especially with local students, in order to reduce social isolation. In addition, they could act as a venue for students to exchange their living and learning experiences.

3. Chinese universities could help international students by recommending useful apps for them to install on their electronic devices. These apps could inform them about how to get around in the university or the city, how to learn and use the Chinese language, how to work through their academic degree studies, or how to prepare for high-stakes examinations, such as the HSK. Social media apps may also help them to develop social networks with local Chinese students and other international students.

4. In addition to apps, Chinese universities need to ensure that international students are well informed about the different aspects of Chinese university life and studies. For instance, a student guide for international students could be compiled to include details about course assessments, HSK tests, scholarship systems and study plans for different academic degrees. The standards and expectations for assessment need to be clearly communicated to international students, since their assessment results determine their future studies.

5. Since the HSK test focuses on grammar, structure and vocabulary [34], Chinese language teachers may need to redesign their courses and develop appropriate learning materials in a reasonably-paced plan. It seems that the teachers need to be more engaged in responding to the learning needs of international students like our participants. Suggestions such as developing individualized curricula and students' potential can be taken into consideration [35]. For instance, specific teaching resources and methods can be provided for a certain group of students (e.g. the Uzbekistani students in this context) which differs from the one for other international students group. they might need to focus on all of the aspects of Chinese learning, including listening, speaking, reading and writing. When the international students feel that their needs are fully acknowledged, Chinese language teachers may then introduce cultural content through a variety of strategies, such as using documentary films, presenting narratives about China from a foreigner's perspective, and conducting group discussions. Such pedagogical strategies may help international students, such as the Uzbekistani students in our study, to understand the cultural gaps that they experience upon their arrival in China, and enable them to feel more motivated to learn about the Chinese language and culture. 


\section{Conclusions}

In this study, we explored and identified the salient factors in a group of Uzbekistani students' language learning demotivation, so that we could work out practical suggestions to sustain their learning of Chinese in Chinese universities. We appreciate that the study has a few methodological limitations. The sample size was too small for us to conduct sophisticated statistical analysis. The participant group contained too many males in comparison with females, since the university attracted many more male students from Uzbekistan. The Chinese language proficiency of the participants was limited to the elementary and intermediate level; no students with advanced Chinese language proficiency were included in the participant group. Besides this, this study was conducted in a diglossic context (Hangzhou city), where not everyone speaks Putonghua; the outcome of this research could be partially replicated in similar Chinese language education contexts in China in order to strengthen the administration of foreign students in China, reduce their demotivation and maintain the Chinese language learning ability among foreign students. Therefore, it is important to be cautious when applying the findings to all Uzbekistani or international students in all of the regions of China.

Nevertheless, the findings did help us to offer important suggestions for language educators and educational administrators, which are significant because our identified sources of demotivation do require attention, and international students like our participants are in need of care, guidance and support in learning Chinese and adapting themselves to their new educational context. Our suggestions, if implemented, will help to sustain the motivation of all international students, including Uzbekistani students, while they are learning Chinese. However, further research on these and other international students studying in China is needed in order to ensure sustainable multilingualism in Chinese universities.

Author Contributions: Conceptualization, M.L., Y.Z.; methodology, X.M.; validation, Y.Z., X.M.; formal analysis, Y.W.; investigation, M.L., Y.W.; data curation, Y.Z.; writing—original draft preparation, M.L., Y.W.; writing一review and editing, M.L., Y.W.; supervision, Y.Z.; project administration, Y.Z.; funding acquisition, M.L. All authors have read and agreed to the published version of the manuscript.

Funding: This research was funded by the research program of the 10th Chinese Foreign Language Education Fund (grant number ZGWYJYJJ10A036).

Acknowledgments: We sincerely thank Andy Gao for his consistent support for the paper. Our gratitude also goes to those teacher and student participants and administrators who took the time to collaborate with us to carry out the questionnaires and interviews.

Conflicts of Interest: The authors declare no conflict of interest.

\section{Appendix A}

The questionnaire and descriptive analysis results.

Table A1. Questions and descriptive statistics.

\begin{tabular}{|c|c|c|c|c|c|c|}
\hline No. & Question & $\begin{array}{l}\text { Minimum } \\
\text { Value }\end{array}$ & $\begin{array}{l}\text { Maximum } \\
\text { Value }\end{array}$ & $\begin{array}{l}\text { Average } \\
\text { Value }\end{array}$ & $\begin{array}{l}\text { Standard } \\
\text { Deviation }\end{array}$ & Median \\
\hline 1 & I think the textbook is not suitable for me & 1 & 5 & 3.061 & 0.966 & 3 \\
\hline 2 & $\begin{array}{l}\text { The content of the textbook is old or } \\
\text { not practical }\end{array}$ & 1 & 5 & 2.848 & 1.121 & 3 \\
\hline 3 & There are too many students in the class & 1 & 5 & 3.121 & 1.244 & 3 \\
\hline 4 & $\begin{array}{l}\text { The Chinese level of the class is too } \\
\text { high/low for me }\end{array}$ & 2 & 5 & 3.182 & 0.917 & 3 \\
\hline 5 & $\begin{array}{l}\text { Dissatisfied with the } \\
\text { classroom environment }\end{array}$ & 1 & 5 & 3.152 & 1.121 & 3 \\
\hline
\end{tabular}


Table A1. Cont.

\begin{tabular}{|c|c|c|c|c|c|c|}
\hline No. & Question & $\begin{array}{l}\text { Minimum } \\
\text { Value }\end{array}$ & $\begin{array}{l}\text { Maximum } \\
\text { Value }\end{array}$ & $\begin{array}{l}\text { Average } \\
\text { Value }\end{array}$ & $\begin{array}{l}\text { Standard } \\
\text { Deviation }\end{array}$ & Median \\
\hline 6 & $\begin{array}{l}\text { Frequent replacement of teachers has } \\
\text { affected my learning }\end{array}$ & 1 & 5 & 3.182 & 1.236 & 3 \\
\hline 7 & The course setting is not reasonable & 1 & 5 & 2.939 & 0.998 & 3 \\
\hline 8 & It's hard to adapt to the school schedule & 1 & 5 & 2.909 & 1.308 & 3 \\
\hline 9 & The class's leave is too strict & 1 & 5 & 3 & 1.061 & 3 \\
\hline 10 & $\begin{array}{l}\text { The school's library has insufficient } \\
\text { resources, too few seats etc. }\end{array}$ & 1 & 5 & 3.03 & 1.075 & 3 \\
\hline 11 & $\begin{array}{l}\text { I don't like some teachers; I don't like } \\
\text { his/her character }\end{array}$ & 1 & 5 & 2.818 & 0.983 & 3 \\
\hline 12 & $\begin{array}{l}\text { Some teachers speak too fast, I can't } \\
\text { keep up }\end{array}$ & 1 & 5 & 2.848 & 1.064 & 3 \\
\hline 13 & $\begin{array}{l}\text { I don't like some teachers' } \\
\text { teaching methods }\end{array}$ & 1 & 5 & 2.879 & 1.083 & 3 \\
\hline 14 & $\begin{array}{l}\text { The teacher's own language ability is not } \\
\text { good, sometimes I don't understand what } \\
\text { he/she is saying }\end{array}$ & 1 & 5 & 3.03 & 1.104 & 3 \\
\hline 15 & $\begin{array}{l}\text { The teacher's level of knowledge is not } \\
\text { that high, and students' questions cannot } \\
\text { be answered during class }\end{array}$ & 1 & 5 & 3.061 & 1.116 & 3 \\
\hline 16 & $\begin{array}{l}\text { The teacher's requirements for us are very } \\
\text { strict, and assignments are a lot/hard }\end{array}$ & 1 & 5 & 3.364 & 0.994 & 3 \\
\hline 17 & $\begin{array}{l}\text { The teacher always talks a lot. There is no } \\
\text { opportunity for students to practice oral } \\
\text { Chinese. I have few chances to speak }\end{array}$ & 1 & 5 & 2.727 & 1.008 & 3 \\
\hline 18 & $\begin{array}{l}\text { I feel sad when I encounter frustration in } \\
\text { communicating with teachers }\end{array}$ & 1 & 5 & 3.03 & 1.075 & 3 \\
\hline 19 & $\begin{array}{l}\text { The teacher did not encourage me when I } \\
\text { made progress }\end{array}$ & 1 & 5 & 2.879 & 0.992 & 3 \\
\hline 20 & $\begin{array}{l}\text { The class is very dull, because the teacher } \\
\text { is always very serious in classes }\end{array}$ & 1 & 5 & 3 & 1.146 & 3 \\
\hline 21 & $\begin{array}{l}\text { The teachers always waste time on those } \\
\text { students who are not learning }\end{array}$ & 1 & 5 & 3 & 1.031 & 3 \\
\hline 22 & $\begin{array}{l}\text { Team members are unwilling to cooperate } \\
\text { when doing group work }\end{array}$ & 1 & 5 & 3 & 0.968 & 3 \\
\hline 23 & $\begin{array}{l}\text { The negative attitudes of friends and } \\
\text { classmates in learning Chinese have } \\
\text { influenced me. }\end{array}$ & 1 & 5 & 2.879 & 1.269 & 3 \\
\hline 24 & $\begin{array}{l}\text { Although I study hard, my Chinese level } \\
\text { has not improved or improved slowly. }\end{array}$ & 1 & 5 & 3.606 & 1.059 & 4 \\
\hline 25 & $\begin{array}{l}\text { I am not willing to speak Chinese with } \\
\text { my classmates }\end{array}$ & 1 & 5 & 3 & 1.369 & 3 \\
\hline 26 & $\begin{array}{l}\text { I am worried that I would be mocked } \\
\text { because of my Chinese }\end{array}$ & 1 & 5 & 2.788 & 1.244 & 3 \\
\hline 27 & $\begin{array}{l}\text { The other foreign language I am learning } \\
\text { affects my Chinese learning }\end{array}$ & 1 & 5 & 2.848 & 1.349 & 3 \\
\hline 28 & $\begin{array}{l}\text { I feel that the exam results do not reflect } \\
\text { my true Chinese proficiency }\end{array}$ & 1 & 5 & 3.394 & 1.298 & 3 \\
\hline 29 & $\begin{array}{l}\text { I was less interested in learning Chinese } \\
\text { when I got a bad test score }\end{array}$ & 1 & 5 & 3.061 & 1.273 & 3 \\
\hline
\end{tabular}


Table A1. Cont.

\begin{tabular}{clccccc}
\hline No. & \multicolumn{1}{c}{ Question } & $\begin{array}{c}\text { Minimum } \\
\text { Value }\end{array}$ & $\begin{array}{c}\text { Maximum } \\
\text { Value }\end{array}$ & $\begin{array}{c}\text { Average } \\
\text { Value }\end{array}$ & $\begin{array}{c}\text { Standard } \\
\text { Deviation }\end{array}$ & Median \\
\hline 30 & $\begin{array}{l}\text { I feel that the scores of the grades are } \\
\text { unfair and the scholarships are } \\
\text { unfairly distributed }\end{array}$ & 1 & 5 & 3.212 & 1.193 & 3 \\
\hline 31 & My interest in Chinese is not very strong & 1 & 5 & 2.545 & 1.227 & 3 \\
\hline 32 & I think Chinese is too difficult & 1 & 5 & 3.515 & 1.093 & 4 \\
\hline 33 & $\begin{array}{l}\text { There is no cultural activity/association for } \\
\text { international students to participate in }\end{array}$ & 1 & 5 & 3.515 & 1.093 & 3 \\
\hline 34 & There is no language support group & 1 & 5 & 3.394 & 1.321 & 3 \\
\hline
\end{tabular}

\section{References}

1. De Burgh-Hirabe, R. Motivation to learn Japanese as a foreign language in an English-speaking country: An exploratory case study in New Zealand. System 2019, 80, 95-106. [CrossRef]

2. Dörnyei, Z. Teaching and Researching Motivation; Longman: London, UK, 2001.

3. Dörnyei, Z. The Psychology of the Language Learner: Individual Differences in Second Language Acquisition; Erlbaum: Mahwah, NJ, USA, 2005.

4. Dörnyei, Z. Towards a better understanding of the L2 Learning Experience, the Cinderella of the L2 Motivational Self System. Stud. Second Lang. Learn. Teach. 2019, 9, 19-30. [CrossRef]

5. Fryer, L.K. Getting interested: Developing a sustainable source of motivation to learn a new language at school. System 2019, 86, 102-120. [CrossRef]

6. Gong, Y.; Gao, X.; Lyu, B. Teaching Chinese as a second or foreign language to non-Chinese learners in mainland China (2014-2018). Lang. Teach. 2020, 53, 44-62. [CrossRef]

7. Gong, Y.; Hu, X.; Lai, C. Chinese as a second language teachers' cognition in teaching intercultural communicative competence. System 2019, 78, 224-233. [CrossRef]

8. Wan, Z.; Gao, X. English or Chinese as medium of instruction? International students' perceptions and practices in Chinese universities. Engl. Today 2020, 36, 37-44. [CrossRef]

9. Kikuchi, K. Listening to our learners' voices: What demotivates Japanese high school students? Lang. Teach. Res. 2009, 13, 453-471. [CrossRef]

10. Kearney, P.; Plax, T.G.; Allen, T.H. Understanding student reactions to teachers who misbehave. In Communication for Teachers; Chesebro, J.L., McCroskey, J.C., Eds.; Allyn \& Bacon: Boston, MA, USA, 2002; pp. 127-140.

11. Millette, D.M.; Gorham, J. Teacher behavior and student motivation. In Communication for Teachers; Chesebro, J.L., McCroskey, J.C., Eds.; Allyn \& Bacon: Boston, MA, USA, 2002; pp. 141-153.

12. Potee, N. Teacher immediately and student motivation. In Sociocultural Influences on Motivation and Learning: A Historical Perspective; McInerney, D.M., Van Etten, S., Eds.; Information Age Publishing: Greenwich, CT, USA, 2002; pp. 207-223.

13. Trang, T.; Baldauf, R.B. Demotivation: Understanding Resistance to English Language Learning-The Case of Vietnamese Students. J. Asia TEFL 2007, 4, 79-105.

14. Falout, J.; Maruyama, M. A comparative study of proficiency and learner demotivation. Lang. Teach. 2004, 28, 3-10.

15. Kikuchi, K. Learner perceptions of demotivators in Japanese high school English classrooms. Ph.D. Thesis, Temple University, Tokyo, Japan, 2001. Unpublished.

16. Kikuchi, K. Demotivators in the Japanese EFL context. In Language Learning Motivation in Japan; Apple, M.T., Da Silva, D., Fellner, T., Eds.; Multilingual Matters: Bristol, UK, 2013; pp. 206-224.

17. Kikuchi, K. Demotivation in Second Language Acquisition: Insights from Japan; Multilingual Matters: Bristol, UK, 2015.

18. Oxford, R.L. The bleached bones of a story: Learners constructions of language teachers. In Leaners Contributions to Language Learning; Breen, M.P., Ed.; Longman: Harlow, UK, 2001; pp. 86-111.

19. Sakai, H.; Kikuchi, K. An Analysis of Demotivators in the EFL Classroom. System 2009, 37, 57-69. [CrossRef]

20. Tsuchiya, M. Factors in demotivation concerning learning English: A preliminary study of Japanese university students. Kyushu Acad. Soc. Engl. Lang. Educ. 2004, 32, 39-46. 
21. Arai, K. What demotivates "language learners"? Qualitative study on demotivational factors as perceived by undergraduates. Eur. Sci. J. 2004, 9, 365-382.

22. Chang, S.M.; Cho, C.H. Demotivating Factors in Foreign Language Learning. In the Twelfth International Symposium on English Teaching; Crane Publishing: Taipei, Taiwan, 2003; pp. 257-264.

23. Zhang, L. A Study of College Students' Classroom Motivational Ailments in College English Teaching; Shandong Normal University: Jinan, Shandong, China, 2008.

24. Zhang, W.; Ding, A.Q. Grounded-theory Analysis of the Demotivation in Second Language Learning. J. Ocean Univ. China Soc. Sci. 2018, 3, 117-123.

25. Yu, W.Q. An Analysis of Factors Effecting Demotivation of Foreign Students' Chinese learning. Lang. Teach. Linguist. Stud. 2013, 3, 24-31.

26. Xu, S.J. Research on Motivational Factors of Chinese Language Learning in Turkey: A Case Study of Chinese Learners in Istanbul. J. Gansu Radio Telev. Univ. 2019, 6, 85-90.

27. Demberel, U. The Problem of Demotivation in Chinese Language Learning of Mongolian Students-Case Study of the Mongolian State University of Science and Technology; Zhejiang University: Hangzhou, Zhejiang, China, 2019.

28. Jeong, S. Research on the De-motivation of Chinese Learning among Korean University Students; Beijing Foreign Studies University: Beijing, China, 2019.

29. Pretty, T. Demotivation in a Chinese language classroom a case of UZCI students. Int. J. Multidiscip. Curr. Educ. Res. 2019, 6, 1-10.

30. Hamadziripi, E.V.; Mkize, F.S. Motivation in Foreign Language Learning: A Case Study of Adult Learners of Chinese in Zimbabwe. IOSR J. Hum. Soc. Sci. 2019, 24, 7-23.

31. Ko, E. An Investigation into Chinese Learning Motivation and Demotivation of Korean Students Studying Abroad in China; Beijing International Studies University: Beijing, China, 2018.

32. Li, D.C.S. Chinese as a lingua franca in Greater China. Ann. Rev. Appl. Linguist. 2006, 26, 149-176. [CrossRef]

33. Lu, J.J. A Dialogue on HSK: Some Suggestions on the Improvement of HSK. TCSOL Stud. 2018, 72, 44-49.

34. Jiang, L.P. The Underlying Idea and Practice of HSK Standard Course. J. Int. Chin. Teach. 2015, 2, 53-59.

35. Li, C.; Abrar-ul-Hassan, S.; Gao, F. An Ecological Perspective on University Students' Sustainable Language Learning during the Transition from High School to University in China. Sustainability 2020, 12, 7359. [CrossRef] 